\title{
Indications for Gastrointestinal Endoscopy during the COVID-19 Pandemic
}

\author{
Deepak Gunjan,๑ Pramod Garg ${ }^{1}$ \\ ${ }^{1}$ Department of Gastroenterology and Human Nutrition Unit, \\ All India Institute of Medical Sciences, New Delhi, India
}

\begin{abstract}
Address for correspondence Dr. Deepak Gunjan, MD, DM, Department of Gastroenterology and Human Nutrition Unit, Room No-3111, 3rd floor, Teaching Block, All India Institute of Medical Sciences, New Delhi 110029, India

(e-mail: drdg_01@rediffmail.com).
\end{abstract}

\begin{abstract}
Keywords

- COVID-19

- severe acute respiratory syndrome

- coronavirus

- gastrointestinal endoscopy

The global pandemic due to COVID-19 presents an unprecedented challenge to mankind including healthcare providers. Many COVID-19 infected patients may present with gastrointestinal symptoms. Endoscopic services may be required in complicated COVID-19 infected or suspected patients. In addition, resource allocation would demand judicious use of endoscopy services. There is a definite risk of transmission of COVID-19 during endoscopy to healthcare professionals. We recommend that only emergency and life-saving endoscopic procedures should be performed during COVID-19 pandemic, and semi-elective procedures should be performed after careful consideration. All routine endoscopy procedures should be deferred till normal hospital services resume. For emergency endoscopy procedures, prescreening of patients is critical to avoid nosocomial transmission. To prevent cross-infection among healthcare professionals, strict infection control measures should be practiced in endoscopy suite while providing essential endoscopic services to the patients.
\end{abstract}

\section{Introduction}

COVID-19 is ravaging the world and has been declared a global pandemic by the World Health Organization (WHO). By April 18, 2020, it has spread its tentacles to more than 200 countries, infected $>2$ million people, and led to the death of $>150,000$ patients. COVID-19 spreads through person-toperson contact, aerosols and droplet infection, and there is growing evidence that it might be airborne too., ${ }^{1,2}$ Initially, it was thought that it presented with predominantly respiratory symptoms, but recently various series have shown that many patients developed gastrointestinal (GI) manifestations in the form of diarrhea, anorexia, nausea, and abdominal pain. In a meta-analysis, the pooled prevalence of all GI symptoms was $17.6 \%$ : $11.8 \%$ of patients with nonsevere COVID-19 and $17.1 \%$ of patients with severe COVID19 had GI symptoms, respectively. ${ }^{3}$ Approximately, $48 \%$ stool samples were positive for viral RNA and surprisingly $70 \%$ of these stool samples were persistently positive for viral RNA even after viral clearance was documented in the respiratory samples, raising the possibility of feco-oral transmission. ${ }^{3}$ A few studies have indeed suggested that feco-oral transmission of COVID-19 is possible., ${ }^{4,5}$ Therefore, gastroenterologists should be cognizant of the GI involvement by COVID-19.

Various receptors have been identified as potential binding sites for COVID-19 in humans. ${ }^{6}$ Angiotensin-converting enzyme 2 (ACE-2) receptor is the most common and well-defined host-cell binding receptor for COVID-19 spike protein which mediates its entry to the host cell. ${ }^{6}$ ACE-2 receptor are abundantly present on liver cholangiocytes, colonocytes, esophageal keratinocytes, ileum enterocytes, rectum enterocytes, and gastric epithelial cells, explaining COVID19's predilection for GI tract. ${ }^{6,7}$ This might be the plausible explanation for GI manifestations of COVID-19 and probably responsible for feco-oral transmission as well. ${ }^{3,8,9}$ 


\section{Risk of COVID-19 Infection During Endoscopy}

GI endoscopy is essential for various diagnostic and therapeutic purposes. It is also commonly used for screening and surveillance programmes. Due to the ongoing COVID-19 pandemic, it has become difficult to perform routine endoscopic procedures. GI endoscopy is a contact and aerosol generating procedure, and healthcare workers (HCWs) do come in contact with body fluids (like blood, vomitus, secretions, lavage fluid, and fecal matter). Many of the advanced therapeutic procedures also require general anesthesia and mechanical ventilation, which are aerosol-generating procedures and pose a significant risk to the anesthesiologists and endoscopy staffs.

Sputum, blood, and fecal matter have shown presence of viral RNA and can effectively transmit infection., ${ }^{50-12}$ Therapeutic endoscopy is especially time consuming, rendering the endoscopists and staff more vulnerable due to increased exposure time to infectious agents. Colonoscopy is generally believed not to generate aerosol; however, it is not without risks. In one of the studies, bioaerosol burden in the endoscopy suite was four times at the end of daily colonoscopy program as compared with beginning of the procedures..$^{13}$ Many studies have also proposed feco-oral transmission of COVID-19.12 Viral RNA has been shown to be persistently present in anal swab. ${ }^{5,12,14}$ Therefore, colonoscopy also should be considered as an aerosol-generating procedure mandating precaution.

A study has illustrated that endoscopists are at high-risk of exposure to infected biological samples which is a potential source for transmission of infectious disease. ${ }^{15}$ In addition, this study revealed that approximately $60 \%$ of those who were not in direct contact of patients also had bacterial contamination. ${ }^{15}$ Another study showed that therapeutic or diagnostic endoscopy has similar rates of mucocutaneous exposure of infected biological samples from patients. ${ }^{16}$ Thus, endoscopists are definitely at increased risk of getting exposure to infected biological materials. A study by Akyuz et al reported that neither endoscopists and endoscopy nurses effectively used universal precautions against the risk of infection nor did they receive training for the same. ${ }^{7}$ This simply suggests that there is a lackadaisical approach on the part of the endoscopists and HCWs when it comes to taking enough precautions during endoscopy procedures. In addition, there is a shortage of personal protective equipment (PPE) and respirators in most of the hospitals during the pandemic, making HCWs more prone for exposure to COVID-19. ${ }^{17}$

\section{Judicious Use of Endoscopic Procedures}

One strategy to prevent cross-contamination involves restricting the use of endoscopy during the active spread of COVID19. By restricting endoscopic procedures, endoscopists will have less chances of exposure to infection. This will also give adequate time to sterilize the instruments, clean floors, walls and trolleys, and lead to fewer chances of lapses in decontamination procedures. Availability of negative pressure room for endoscopy can significantly reduce the chance of airborne infection, but that is a rare commodity in most of the endoscopy suites. ${ }^{18}$ Many of HCWs have been reported to have contracted COVID-19, and many have died due to COVID-19 exposure, reducing the workforce and increasing the burden on the healthcare system. ${ }^{17,19,20}$ Weighing all these risks, therefore, we should choose endoscopic procedures which outweigh the risks of infection to HCWs compared with the benefits to the patients. One must also keep in mind that HCWs may also propagate the infection within the system.

\section{Triaging Before Endoscopy}

In general, routine elective endoscopic procedures should be deferred. The reasons are as follows:

1. Risk of infection.

2. Lack of availability of widespread testing.

3. Risk of transmission even from asymptomatic patients.

4. Optimal utilization of resources such as personal protection equipment (PPE).

5. Posting of personnel for COVID-19 duties.

6. Risk versus benefit.

7. Risk of procedure-related complications and difficulty of managing them.

GI endoscopy is not performed in sterile environment unlike surgery. Therefore, as discussed earlier, exposure to HCWs by cross-contamination is a definite possibility. Risk of infection is also higher because endoscopic procedures demand short physical distance between endoscopists, endoscopy staff, and the patient. Another major hurdle during COVID-19 epidemic is lack of availability of widespread testing due to resource constraint and nonavailability of modern diagnostic laboratory at many places for reverse transcription polymerase chain reaction (RT-PCR) tests. Rapid antibody-based tests are a way forward but false-negative results during incubation period will still be a problem. Asymptomatic COVID-19 infected patients will be another concern, because it will be difficult to diagnose them even after careful evaluation. Globally, there is shortage of HCWs due to posting of personnel for COVID19 duties, and illness and death due to COVID-19 infection. There is also dearth of PPE in many countries including India and various other limitations in resource constraint settings. All these factors make it difficult to run endoscopy services at full pace. Yet, emergency endoscopy services must be provided.

Patients should be triaged into three different categories, depending on the likelihood of benefit of endoscopy and change in management after endoscopic procedures (-Fig. 1). ${ }^{21}$ Elective diagnostic endoscopy is unlikely to yield immediate benefit and change the immediate management of the patient. For example, follow-up endoscopy for Barrett's esophagus, surveillance colonoscopy, endoscopy for dyspepsia and nonspecific abdominal pain, etc., are unlikely to be of much benefit. Urgent endoscopy that will provide immediate benefit with intervention include endoscopy for GI bleeding and endoscopic retrograde cholangio-pancreatography (ERCP) for acute cholangitis. 


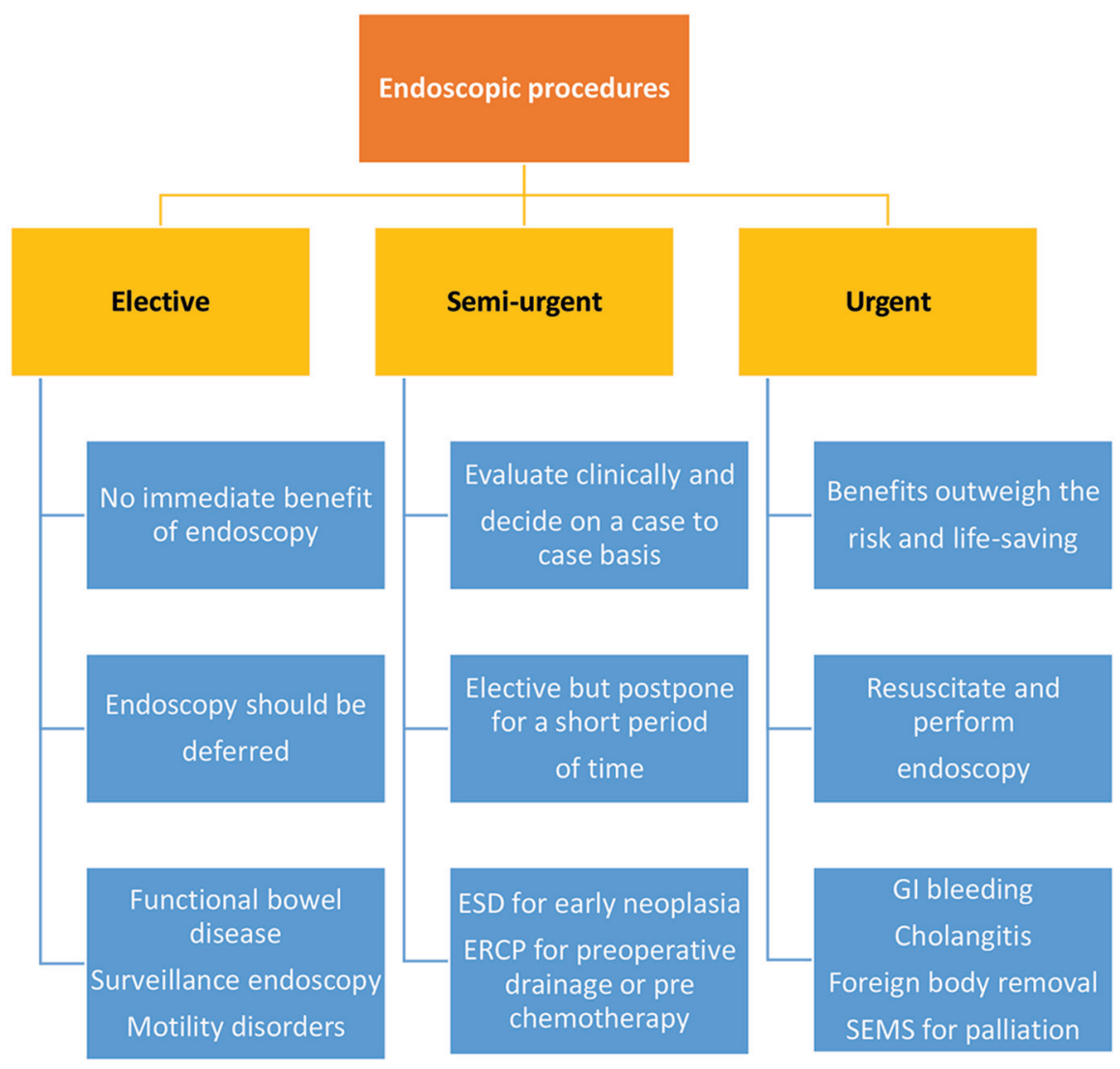

Abbreviation:

ERCP: endoscopic retrograde cholangiopancreatography; ESD: endoscopic submucosal

dissection; GI: gastrointestinal; SEMS: self-expanding metal stent

Fig. 1 Classification of endoscopic procedures depending on urgency of endoscopy requirement in COVID-19 positive patients.

Table 1 Indications for endoscopy

\begin{tabular}{|c|c|c|}
\hline Urgent/Emergency Indications & Semiurgent Indications & Elective Indications \\
\hline $\begin{array}{l}\text { 1. Upper and lower GI bleeding } \\
\text { 2. Acute cholangitis } \\
\text { 3. Palliation for luminal obstruction } \\
\text { like esophageal, gastric or colonic } \\
\text { obstruction } \\
\text { 4. Postsurgical leak correction by OTSC, } \\
\text { clip or SEMS placement } \\
\text { 5. Feeding tube placement } \\
\text { 6. Endoscopic drainage and lavage in } \\
\text { patients with infected pancreatic } \\
\text { collections } \\
\text { 7. Foreign bodies removal } \\
\text { 8. Evaluation of significant symptoms, } \\
\text { for example, malignancy }\end{array}$ & $\begin{array}{l}\text { 1. Strong suspicion of GI malignancy } \\
\text { 2. Fecal occult blood test positive } \\
\text { without alarm features } \\
\text { 3. Repeat endoscopy for variceal } \\
\text { obliteration, healing of peptic ulcer } \\
\text { 4. ESD/EMR for early neoplasia } \\
\text { 5. ERCP for preoperative biliary drainage } \\
\text { if patient is planned for surgery or } \\
\text { prior to chemotherapy } \\
\text { 6. EUS for malignancy if patient planned } \\
\text { for surgery } \\
\text { 7. Endoscopic drainage if significant } \\
\text { symptoms due to pancreatic fluid } \\
\text { collections }\end{array}$ & $\begin{array}{l}\text { 1. Screening endoscopy: colorectal } \\
\text { cancer screening, variceal screening, } \\
\text { Barrett's screening } \\
\text { 2. Functional bowel disease like } \\
\text { dyspepsia, functional constipation, } \\
\text { irritable bowel syndrome, } \\
\text { abdominal pain } \\
\text { 3. Endoscopy for suspected motility } \\
\text { disorders } \\
\text { 4. Gl symptoms with no alarm features } \\
\text { 5. Routine diagnostic endoscopy } \\
\text { 6. ERCP and EUS in benign conditions }\end{array}$ \\
\hline
\end{tabular}

Abbreviations: EMR, endoscopic mucosal resection; ERCP, endoscopic retrograde cholangiopancreatography; ESD, endoscopic submucosal dissection; EUS, endoscopic ultrasonography; GI, gastrointestinal; OTSC, over the scope clip; SEMS, self-expanding metal stent.

Semiurgent endoscopy should be evaluated properly and can be decided on a case-to-case basis, taking into account the availability of resources and likely benefit to the patient, for example, endoscopy for fecal occult blood test positive without alarm features, repeat endoscopy for variceal obliteration, and endoscopy for high suspicion of malignancy (-Table 1). Performing endoscopies only for urgent indications will reduce the number of endoscopies significantly. 
The decision to perform endoscopy and ascertain its indications should be taken by senior gastroenterologists/endoscopists. All endoscopies should be performed by experienced endoscopists and not by the trainees. This is also true for the endoscopy nursing assistants. It will decrease the number of unnecessary endoscopies and will reduce the burden on the endoscopy suite, especially at a time when many of the endoscopy staffs in hospitals have been assigned to COVID19 designated duties. ${ }^{17,19}$

Even for urgent endoscopy procedures, patients should not be rushed to the endoscopy suite. Proper history should be taken regarding travel, fever, respiratory and GI symptoms and then triage them in terms of the risk of COVID-19 infection before taking to endoscopy. ${ }^{21,22}$ If any contraindication to endoscopy is found, it should not be attempted. Many studies have shown that urgent and early endoscopy in acute upper GI bleeding have similar outcomes. ${ }^{23-25}$ Similarly, in acute lower GI bleeding, early colonoscopy compared with elective one does not benefit in terms of rebleeding, hospital stay, and mortality. ${ }^{26-28}$ In patient with acute cholangitis with varying severity, most of the patients respond to aggressive hydration and IV antibiotics, and $20-30 \%$ of patients with severe cholangitis require biliary drainage. ${ }^{29}$ ERCP is the best method for biliary drainage in patients with acute cholangitis, and emergent ERCP within 48 hours reduces mortality, hospital stay and organ failures. ${ }^{29}$ However, these patients should be properly resuscitated and medically optimized before ERCP. This is also important because these patients poorly tolerate endoscopic procedures and sedation. Therefore, meticulous clinical history and triage, optimum stabilization, and ascertaining proper indication are prerequisites for endoscopy, and patients should not be rushed for emergency endoscopic procedures. ${ }^{30}$

In the endoscopy suite, one should arrange all endoscopic accessories that are likely to be used for a specific procedure, so that procedure time can be reduced. Minimal number of endoscopy personnel should be involved during the procedure to reduce the risk of exposure. Fellow training should be stopped to reduce exposure and for optimal utilization of PPE. Endoscope function should be carefully checked before starting the procedure.

\section{Indications of Endoscopy}

Patients should be categorized into low-, intermediate- and high-risk on the basis of potential risk of COVID-19 infection to HCWs. ${ }^{22}$ Non-COVID-19 patients should be considered low-risk category. COVID-19 positive or highly suspect patients, and if adequate patient history cannot be assessed, should be labeled as high-risk category. ${ }^{21,22}$ Those patients who recovered from COVID-19 infection within the past 2 weeks should be considered as high-risk due to persistence of viral RNA in feces beyond 2 weeks. ${ }^{3-5}$ Another worrying trend is the reactivation of COVID-19 infection in previously cured patients. ${ }^{31}$ These patients should also be considered as high-risk. These categorizations will also help in rational use of equipment and PPE in the endoscopy suite.

Elective endoscopic procedures should be deferred for all risk categories. Urgent endoscopic procedures should not be withheld for any risk categories. Semiurgent endoscopic procedures should be temporarily postponed for a reasonable period of time and decided on a case-to-case basis, for example, endoscopic submucosal dissection (ESD) for high-grade dysplasia or intramucosal carcinoma should not be withheld indefinitely. However, stepwise resumption of elective and semiurgent endoscopy services should be implemented, depending on control of COVID-19 in the local community, and availability of equipment, PPE and manpower.

\section{Endoscopy in non-COVID-19 Patients}

Various endoscopic societies have recommended that only emergency and urgent endoscopy should be performed. ${ }^{21,32}$ The indications which require urgent endoscopic intervention and immediate care include acute GI bleeding, acute cholangitis, luminal obstruction requiring metal stent placement, feeding tube placement, postsurgical leaks, and iatrogenic perforations ( - Table $\mathbf{1}$ ). In some cases, we should take help of our intervention radiology colleagues, for example, percutaneous biliary drainage, especially in hilar block, ${ }^{33}$ and computed tomogram angiography followed by digital subtraction angiogram for obscure overt bleeding rather than deep enteroscopy. ${ }^{30}$

In choledocholithiasis, if there is no cholangitis and/ or severe pain, immediate ERCP should be deferred, and patients should be apprised of complications and followed-up subsequently. Need for laser or mechanical lithotripsy and cholangioscopy should be avoided because of their complex nature, requirement for more staffs, and being time-consuming in patients with large common bile duct (CBD) stone and biliary stricture, respectively. For symptomatic large CBD stone, laparoscopic surgery is an alternative option. In uncomplicated concomitant gallbladder and CBD stones, single-stage laparoscopic strategy is better in terms of shorter hospital stay, need for fewer procedures, and cost-effectiveness than ERCP. ${ }^{34}$

Endoscopic ultrasound (EUS) should be avoided for evaluation of chronic or recurrent acute pancreatitis, intermediate risk category of pancreatic cystic neoplasm, and benign biliary strictures. Fine needle aspiration cytology in a suspected case of malignancy should not be withheld, because it may change the management; and if patients require curative surgery, they should be referred early. For symptomatic walledoff necrosis (WON) and pseudocyst-like worsening systemic inflammatory response syndrome, increasing abdominal pain or gastric outlet obstruction, endoscopic drainage can be contemplated if feasible endoscopically. Otherwise, for symptomatic collections at other sites like paracolic gutter, multiple collections, or extension to pelvis, percutaneous pigtail catheter placement should be done by the intervention radiologist. Asymptomatic WON or pseudocyst should be followed-up. During drainage procedures, one should take extra precautions to avoid contact with infected fluid from biopsy channel or fluid coming out through the oral cavity. There is some preliminary evidence that COVID-19 can cause pancreatic injury (in both exocrine glands and islets), as ACE2 is highly expressed in these cells. ${ }^{35,36}$ COVID-19 infection can 
result in mild pancreatitis and abnormal blood glucose, and similarly severe acute respiratory syndrome (SARS) Corona virus can result in acute diabetes. ${ }^{35-37}$ Therefore, it is a possibility that COVID-19 virus might be present in pancreatic fluid collections and can be potentially infectious.

Finally, advanced therapeutic endoscopy like peroral endoscopic myotomy and endoscopic submucosal dissection should be postponed to a later date. These procedures require mechanical ventilation, posing significant risk to anesthesiologist and endoscopy personnel; therefore, it should be postponed to a later date. Some other procedures like fecal microbiota transplantation should be avoided during COVID19 pandemic. It will be difficult to manage the postprocedure complications because of logistic issues in the hospital. To be aware of our own limitations during this pandemic is important.

\section{Endoscopy in COVID-19 Positive or Highly Suspect Patients}

With the increasing number of patients with covid-19 who are hospitalized, gastroenterologists are likely to get consultation for many of them for endoscopy, particularly GI bleeding. The causes of GI bleeding in such patients are not known but most likely will be related to stress erosions and ulcers in patients with severe disease. In general, the advice should be conservative treatment with proton pump inhibitors, correction of coagulopathy, and transfusion, as required. In a study, six patients with COVID-19 pneumonia who presented with upper GI bleeding were managed conservatively. ${ }^{38}$ Diagnostic endoscopy is highly unlikely to be of any benefit. Only in patients with severe ongoing bleeding with falling hemoglobin and failure of conservative treatment, should one contemplate therapeutic endoscopy.

In conclusion, only emergency and life-saving endoscopic procedures should be done during COVID-19 pandemic. Each endoscopic unit should have their own protocol for patients' flow, and endoscopy staff should be trained in infection control measures. For emergency endoscopy procedures, prescreening of patients is critical to avoid nosocomial transmission. Semielective endoscopy procedures should be done on a case-to-case basis.

\section{Author Contributions}

DG: acquisition of data and drafting of the manuscript; PG: study concept and critical revision of the manuscript.

\section{Conflict of Interest}

We have no conflicts of interest or financial disclosures to make.

\section{References}

1 Santarpia JL, Rivera DN, Herrera V, et al. Transmission potential of SARS-CoV-2 in viral shedding observed at the University of Nebraska Medical Center. medRxiv 2020; (e-pub ahead of print). doi 10.1101/2020.03.23.20039446
2 Morawska L, Cao J. Airborne transmission of SARS-CoV-2: the world should face the reality. Environ Int 2020;139:105730

3 Cheung KS, Hung IFN, Chan PP, et al. Gastrointestinal manifestations of SARS-CoV-2 infection and virus load in fecal samples from the Hong Kong Cohort and Systematic Review and Meta-analysis. Gastroenterology 2020;(April) :S00165085(20)30448-0

4 Wang W, Xu Y, Gao R, et al. Detection of SARS-CoV-2 in different types of clinical specimens. JAMA 2020; (e-pub ahead of print). doi 10.1001/jama.2020.3786

5 Zhang W, Du R-H, Li B, et al. Molecular and serological investigation of 2019-nCoV infected patients: implication of multiple shedding routes. Emerg Microbes Infect 2020;9(1):386-389

6 Qi F, Qian S, Zhang S, Zhang Z. Single cell RNA sequencing of 13 human tissues identify cell types and receptors of human coronaviruses. Biochem Biophys Res Commun 2020;(March) :S0006-291X(20)30523-4

7 Akyüz N, Keskin M, Akyolcu N, et al. How and how much do endoscopy professionals protect themselves against infection? Int J Surg 2014;12(7):720-724

8 Gu J, Han B, Wang J. COVID-19: gastrointestinal manifestations and potential fecal-oral transmission. Gastroenterology 2020;(e-pub ahead of print). doi 10.1053/j.gastro.2020.02.054

9 Nobel YR, Phipps M, Zucker J, et al. Gastrointestinal symptoms and COVID-19: case-control study from the United States. Gastroenterology 2020;(April) :S0016-5085(20)30490-X

10 Chen W, Lan Y, Yuan X, et al. Detectable 2019-nCoV viral RNA in blood is a strong indicator for the further clinical severity. Emerg Microbes Infect 2020;9(1):469-473

11 Han H, Luo Q, Mo F, Long L, Zheng W. SARS-CoV-2 RNA more readily detected in induced sputum than in throat swabs of convalescent COVID-19 patients. Lancet Infect Dis 2020; (e-pub ahead of print). doi 10.1016/S1473-3099(20)30174-2

$12 \mathrm{Xu} \mathrm{Y,} \mathrm{Li} \mathrm{X,} \mathrm{Zhu} \mathrm{B,} \mathrm{et} \mathrm{al.} \mathrm{Characteristics} \mathrm{of} \mathrm{pediatric} \mathrm{SARS-CoV-2}$ infection and potential evidence for persistent fecal viral shedding. Nat Med 2020;26(4):502-505

13 Vavricka SR, Tutuian R, Imhof A, et al. Air suctioning during colon biopsy forceps removal reduces bacterial air contamination in the endoscopy suite. Endoscopy 2010;42(9):736-741

14 Fan Q, Pan Y, Wu Q, et al. Anal swab findings in an infant with COVID-19. Pediatr Investig 2020;4(1):48-50

15 Johnston ER, Habib-Bein N, Dueker JM, et al. Risk of bacterial exposure to the endoscopist's face during endoscopy. Gastrointest Endosc 2019;89(4):818-824

16 Mohandas KM, Gopalakrishnan G. Mucocutaneous exposure to body fluids during digestive endoscopy: the need for universal precautions. Indian J Gastroenterol 1999;18(3):109-111

17 Emanuel EJ, Persad G, Upshur R, et al. Fair allocation of scarce medical resources in the time of COVID-19. N Engl J Med 2020;(e-pub ahead of print).doi 10.1056/NEJMsb2005114

18 Calderwood AH, Day LW, Muthusamy VR, et al; ASGE Quality Assurance in Endoscopy Committee. ASGE guideline for infection control during GI endoscopy. Gastrointest Endosc 2018;87(5):1167-1179

19 Repici A, Pace F, Gabbiadini R, et al; ITALIAN GI-COVID19 Working Group. Endoscopy units and the COVID-19 outbreak: a multi-center experience from Italy. Gastroenterology 2020;(April) :S0016-5085(20)30466-2

20 Zhan M, Qin Y, Xue X, Zhu S. Death from COVID-19 of 23 health care workers in china. N Engl J Med 2020;(e-pub ahead of print). doi 10.1056/NEJMc2005696

21 Chiu PWY, Ng SC, Inoue $\mathrm{H}$, et al. Practice of endoscopy during COVID-19 pandemic: position statements of the Asian Pacific Society for Digestive Endoscopy (APSDE-COVID statements) Gut 2020;(e-pub ahead of print). doi 10.1136/ gutjnl-2020-321185 
22 Repici A, Maselli R, Colombo M, et al. Coronavirus (COVID-19) outbreak: what the department of endoscopy should know. Gastrointest Endosc 2020;(March) :S0016-5107(20)30245-5

23 Bjorkman DJ, Zaman A, Fennerty MB. Lieberman D, Disario JA, Guest-Warnick G. Urgent vs. elective endoscopy for acute non-variceal upper-GI bleeding: an effectiveness study. Gastrointest Endosc 2004;60(1):1-8

24 Lau JYW, Yu Y, Tang RSY, et al. Timing of endoscopy for acute upper gastrointestinal bleeding. N Engl J Med 2020;382(14): 1299-1308

25 Laursen SB, Leontiadis GI, Stanley AJ, Møller MH, Hansen JM, Schaffalitzky de Muckadell OB. Relationship between timing of endoscopy and mortality in patients with peptic ulcer bleeding: a nationwide cohort study. Gastrointest Endosc 2017;85(5):936-944.e3

26 Tsay C, Shung D, Frumento KS, Laine L. Early colonoscopy does not improve outcomes of patients with lower gastrointestinal bleeding: systematic review of randomized trials. Clin Gastroenterol Hepatol 2019;(e-pub ahead of print). doi 10.1016/j.cgh.2019.11.061

27 Nagata N, Niikura R, Sakurai T, et al. Safety and effectiveness of early colonoscopy in management of acute lower gastrointestinal bleeding on the basis of propensity score matching analysis. Clin Gastroenterol Hepatol 2016;14(4):558-564

28 Nigam N, Patel P, Sengupta N. Outcomes of early versus delayed colonoscopy in lower gastrointestinal bleeding using a hospital administrative database. J Clin Gastroenterol 2018; 52(8):721-725

29 Iqbal U, Khara HS, Hu Y, et al. Emergent versus urgent ERCP in acute cholangitis: a systematic review and meta-analysis. Gastrointest Endosc 2020;91(4):753-760.e4

30 Gunjan D, Sharma V, Rana SS, Bhasin DK. Small bowel bleeding: a comprehensive review. Gastroenterol Rep (Oxf) 2014; 2(4):262-275

31 Ye G, Pan Z, Pan Y, et al. Clinical characteristics of severe acute respiratory syndrome coronavirus 2 reactivation. J Infect 2020;80(5):e14-e17
32 Philip M, Lakhtakia S, Aggarwal R, Madan K, Saraswat V, Makharia G. Joint Guidance from the Society of Gastrointestinal Endoscopy of India (SGEI), Indian Society of Gastroenterology (ISG), and Indian National Association for Study of the Liver (INASL) for Gastroenterologists and Gastrointestinal Endoscopists on the prevention, care, and management of patients with COVID-19. Journal of Digestive Endoscopy 2020;(e-pub ahead of print). doi 10.1055/s-0040-1709837

33 Saluja SS, Gulati M, Garg PK, et al. Endoscopic or percutaneous biliary drainage for gallbladder cancer: a randomized trial and quality of life assessment. Clin Gastroenterol Hepatol 2008;6(8):944-950.e3

34 Bansal VK, Misra MC, Rajan K, et al. Single-stage laparoscopic common bile duct exploration and cholecystectomy versus two-stage endoscopic stone extraction followed by laparoscopic cholecystectomy for patients with concomitant gallbladder stones and common bile duct stones: a randomized controlled trial. Surg Endosc 2014;28(3):875-885

35 Wang F, Wang H, Fan J, Zhang Y, Wang H, Zhao Q. Pancreatic injury patterns in patients with COVID-19 pneumonia. Gastroenterology 2020;0(0):S0016-5085(20)30409-1

36 Liu F, Long X, Zou W, et al. Highly ACE2 expression in pancreas may cause pancreas damage after SARS-CoV-2 infection. medRxiv2020;(e-pub ahead of print). doi 10.1101/ 2020.02.28.20029181

37 Yang J-K, Lin S-S, Ji X-J, Guo L-M. Binding of SARS coronavirus to its receptor damages islets and causes acute diabetes. Acta Diabetol 2010;47(3):193-199

38 Cavaliere K, Levine C, Wander P, Sejpal DV, Trindade AJ, Management of upper GI bleeding in patients with COVID-19 pneumonia. Gastrointest Endosc2020;(e-pub ahead of print). doi https://els-jbs-prod-cdn.jbs.elsevierhealth.com/pb/assets/ raw/Health\%20Advance/journals/ymge/GIE-D-20-006901586976896197.pdf 